\title{
ORIGINAL RESEARCH \\ Systematic Review of Methods for Assessing Leptomeningeal Collateral Flow
}

F. McVerry

D.S. Liebeskind K.W. Muir
BACKGROUND AND PURPOSE: The importance of LMF in the outcome after acute ischemic stroke is increasingly recognized, but imaging presents a wide range of options for identification of collaterals and there is no single system for grading collateral flow. The aim of this study was to systematically review the literature on the available methods for measuring LMF adequacy.

MATERIALS AND METHODS: We performed a systematic review of Ovid, MEDLINE, and Embase databases for studies in which flow in the leptomeningeal collateral vessels was evaluated. Imaging technique, grading scale, and reliability assessment for collateral flow measurement were recorded.

RESULTS: We found 81 publications describing 63 methods for grading collateral flow on the basis of conventional angiography $(n=41), \mathrm{CT}(n=7)$, MR imaging $(n=9)$, and transcranial Doppler $(n=6)$. Inter- and/or intraobserver agreement was assessed in only 8 publications.

CoNCLUSIONS: There is inconsistency in how LMF is graded, with a variety of grading scales and imaging modalities being used. Consistency in evaluating collateral flow at baseline is required for the impact of collateral flow to be fully appreciated.

ABBREVIATIONS: $\mathrm{ACA}=$ anterior cerebral artery; $\mathrm{ASL}=$ arterial spin-labeling; $\mid \mathrm{A}=$ intra-arterial; $\mathrm{LMF}=$ leptomeningeal collateral flow; $\mathrm{PCA}=$ posterior cerebral artery; $\mathrm{TCD}=$ transcranial Doppler; $\mathrm{TIMI}=$ Thrombolysis in Myocardial Infarction
L eptomeningeal collaterals are anastomotic vessels providing alternative routes for blood flow in stroke. ${ }^{1}$ In chronic hypoperfusion due to severe carotid stenosis or occlusion, flow via leptomeningeal vessels can maintain cerebral blood flow when primary collateral flow (via the arterial segments of the circle of Willis) is insufficient. ${ }^{2,3}$ Better LMF is associated with less infarct growth and better outcome following acute stroke, ${ }^{4,5}$ while poor collateralization is associated with hemorrhage after IA thrombolysis. ${ }^{6}$ Numerous studies, using several imaging modalities and grading methods, suggest that leptomeningeal collaterals confer a benefit in stroke. Because the influential role of collaterals has been repeatedly reported, we conducted a systematic literature review to investigate the available LMF assessment methods.

\section{Materials and Methods}

MEDLINE and Embase were searched from inception to week 32, 2009, by using the Ovid on-line portal for LMF assessments. The search strategy is shown in Appendix 1. The search was supplemented by review of journal electronic tables of contents and by searching the bibliographies of relevant articles; when full text was unavailable, authors were contacted. Studies that graded LMF, published in English and performed on humans, were considered, with assessments on patients with Moyamoya disease excluded. The target population included patients with acute stroke ( $<24$ hours from onset) or patients with known cerebrovascular disease who had collateral flow assessed at later time points. Studies that graded collateral flow and provided a

Received May 4, 2011; accepted after revision June 24.

From the Institute of Neuroscience and Psychology (F.M., K.W.M.), University of Glasgow, Glasgow, UK; and UCLA Stroke Center (D.S.L.), University of California, Los Angeles, Los Angeles, California.

Please address correspondence to Keith Muir, MD, Institute of Neuroscience and Psychology, University of Glasgow, Institute of Neurological Sciences, Southern General Hospital, Glasgow G51 4TF, Scotland, UK; e-mail: k.muir@clinmed.gla.ac.uk

http://dx.doi.org/10.3174/ajnr.A2794 description of the assessment method were included. Terms such as "cortical/pial anastomoses" were judged as being synonymous with leptomeningeal collaterals and were assessed according to the same criteria. Positron-emission tomography and single-photon emission CT examinations, which indirectly evaluated collaterals, were excluded. Included publication dates ranged from January 1965 to October 2010.

\section{Results}

MEDLINE and Embase searches yielded 9456 and 6847 publications, respectively, 195 of which were screened as relevant and had full texts reviewed. After screening, we included 39 articles. A further 42 articles were obtained by handsearching bibliographies and review of electronic tables of contents, providing a total of 81 different publications for inclusion $(n=$ 4686 patients, Table 1). In total, 41 different criteria for grading LMF with conventional angiography ( $n=3467$ patients), including both acute and nonacute patient groups with collateral assessments in anterior and posterior circulation, were recorded (Table 2). ${ }^{4,6-62}$ Reliability assessments were available for 2 of these methods, demonstrating good and very good inter-/intraobserver agreement $(n=172){ }^{6,14,40}$ Arterial injection sites, when described, included unilateral carotid/MCA $(n=3),{ }^{34,54,56}$ bilateral carotid $(n=3),{ }^{24,52,63}$ a minimum of ipsilateral carotid and vertebral $(n=10),{ }^{9,31,36,38,39,45,51,53,55,58}$ and other combinations $(n=5) \cdot{ }^{10,11,28,49,50}$

Seven grading scales by using CTA were identified, with LMF assessments performed on 593 patients with suspected acute stroke (Table 3).,34,64-73 Interobserver agreement was assessed for 5 CTA methods, ranging from moderate to excellent $(n=247)$. One grading scale used a combination of CTP in addition to CTA to confirm the retrograde direction of true LMF. $^{5}$ MR imaging $(n=358$ patients) and TCD $(n=268$ patients) were used according to 9 and 6 grading methods respectively, with no assessments of interobserver agreement 


\begin{tabular}{lccc}
\hline \multicolumn{4}{l}{ Table 1: Number of LMF assessments per imaging modality } \\
\hline & $\begin{array}{c}\text { Different } \\
\text { Assessment } \\
\text { Methods }\end{array}$ & $\begin{array}{c}\text { No. of } \\
\text { Publications }\end{array}$ & $\begin{array}{c}\text { Studies with } \\
\text { Inter-/Intraobserver } \\
\text { Agreement Assessed }\end{array}$ \\
\hline Angiography & 41 & 58 & $2^{6,14,40}$ \\
CT & 7 & 12 & $5^{5,64,69,71,72}$ \\
MR imaging & 9 & 13 & 0 \\
TCD & 6 & 7 & 0 \\
\hline
\end{tabular}

being reported (Tables 4 and 5). 2,13,19,27,31,35,51,74-86 A total of 8 publications compared noninvasive LMF assessments with MR imaging $(n=5)$, CT $(n=2)$, or TCD $(n=1)$ with a reference standard by using DSA; in each, a different grading scale for the criterion standard was used. ${ }^{13,19,27,31,34-36,51}$

\section{Discussion}

The quality of LMF is reported to be an independent predictor of outcome after acute ischemic stroke, after adjustment for other known prognostic factors such as age, clinical stroke severity, baseline imaging characteristics, occlusion site, treatment, and recanalization/reperfusion ${ }^{4,5,43,63,65,69,72}$ and suggests that, as a minimum, there is a need to account for its influence on outcomes after stroke. Good collateral flow is assumed to be associated with favorable outcome as a consequence of maintaining the ischemic penumbra for longer until reperfusion occurs, though the effect of collaterals appears to be independent of conventional indices of penumbra such as arterial recanalization/reperfusion., ${ }^{5,65}$

It is unclear whether the collateral grade represents an inherent characteristic of individual subjects or a potential therapeutic target. Collateral flow grades on CTA are reportedly better in patients who undergo imaging later after symptom onset, while better collateral flow grades on conventional angiography have been reported in patients treated with statins before stroke, ${ }^{18}$ suggesting that collateral flow is dynamic and could potentially be modified.

The fact that LMF is not accounted for in occlusion classifications may be important in defining arterial occlusions at the entry to a clinical trial and adoption of scoring systems from coronary artery disease; notably, the $\mathrm{TIMI}^{87}$ system or minor modifications of such systems (eg, thrombolysis in cerebral ischemia) ignore fundamental differences in the acquisition of images and the anatomy of the different vascular beds. For example, when applied to the cerebral circulation, a "good" TIMI score on CTA (eg, TIMI 2) could actually represent a complete arterial occlusion (no anterograde flow) with extensive retrograde flow via collaterals. A consistent method for assessment and grading is required to investigate collaterals in acute stroke. Our review revealed wide variation in the methods for grading LMF, few of which are supported even by measurement of observer agreement.

Conventional angiography, considered the criterion standard for assessing cerebrovascular anatomy, can reveal retrograde collateral perfusion in a dynamic fashion and has been used for LMF assessments in the largest number of patients. The most frequently used scale was proposed by the American Society of Interventional and Therapeutic Neuroradiology in an effort to homogenize grading with angiography ${ }^{16}$, but an assessment of interobserver agreement has not yet been reported. Good intraobserver agreement has been demonstrated with angiography when LMF was graded according to the anatomic extent of retrograde flow $(\kappa=0.81){ }^{6,14}$ The Qureshi scale also demonstrates good interobserver agreement but does not focus on LMF independently. One collateral grading scale quantified collateral flow according to the time taken for contrast to travel from the ICA to the M2 segment of the MCA via collaterals but described flow through primary collaterals of the circle of Willis rather than through cortical anastomoses. ${ }^{88}$ Although not truly grading LMF, it provides a quantitative time-based measurement that could potentially be used for collateral assessments. Because LMF is derived from neighboring arterial territories, its quality may only be fully evaluated when the contribution of all potential inflow sources is assessed. Descriptions of arterial injection sites are infrequently provided, and even when available, the contribution of the whole cerebral circulation is seldom evaluated. Conventional angiography is invasive and is usually performed when a patient is being considered for IA therapy which, in general, is reserved for those with contraindications to intravenous treatment (eg, presentation beyond 4.5 hours with favorable appearances on CT), meaning that angiographic LMF assessments are predominantly restricted to this group. Because multimodal CT and MR imaging are increasingly used in clinical practice and before entry to clinical trials, they offer a larger potential population in which LMF can be assessed noninvasively.

Although lacking dynamic information, CTA permits visualization of the extent of LMF. The independent predictive value of collaterals has been confirmed with different CTA methods, and interobserver agreement within different grading scales has been assessed. ${ }^{64,69,71,72}$ Retrograde flow relative to a proximal arterial occlusion provides a measurement of LMF adequacy, but grading LMF this way for more distal occlusions may be more difficult. A collateral scoring system based on contrast enhancement in defined regions of interest provides a scale not dependant on a specific occlusion, which could potentially be applied in a larger patient population. ${ }^{64}$ The addition of CT perfusion to CTA adds important dynamic information to confirm that collateral flow is truly retrograde and demonstrates excellent interobserver agreement. ${ }^{5} \mathrm{New}$ multidetector scanners that enable simultaneous acquisition of both CTA and CTP allow dynamic collateral flow assessment with CT. ${ }^{89}$

LMF assessments with MR imaging use different imaging characteristics to infer the presence of collaterals. FLAIR vascular hyperintensities due to retrograde flow in leptomeningeal vessels have been associated with larger mismatch volumes and smaller subacute infarct volumes, while abnormal vessels on $\mathrm{T} 2{ }^{\star}$ imaging may be due to deoxygenated blood in collaterals and are associated with smaller infarct volumes. ${ }^{80,81}$ ASL, by using different criteria, has also been used to grade collateral flow with MR imaging. ${ }^{13,51,78}$ These and other LMF assessments with MR imaging have not been replicated nor has interobserver reliability been graded, and it remains to be seen if they represent robust means of assessing collateral flow.

Relative blood flow velocity and vessel pulsatility have been used as surrogate markers for leptomeningeal collateral flow by using TCD in a small number of studies, but the criteria for defining LMF varied among publications (Table 5). The lack of an agreed definition for LMF on TCD, absence of direct 


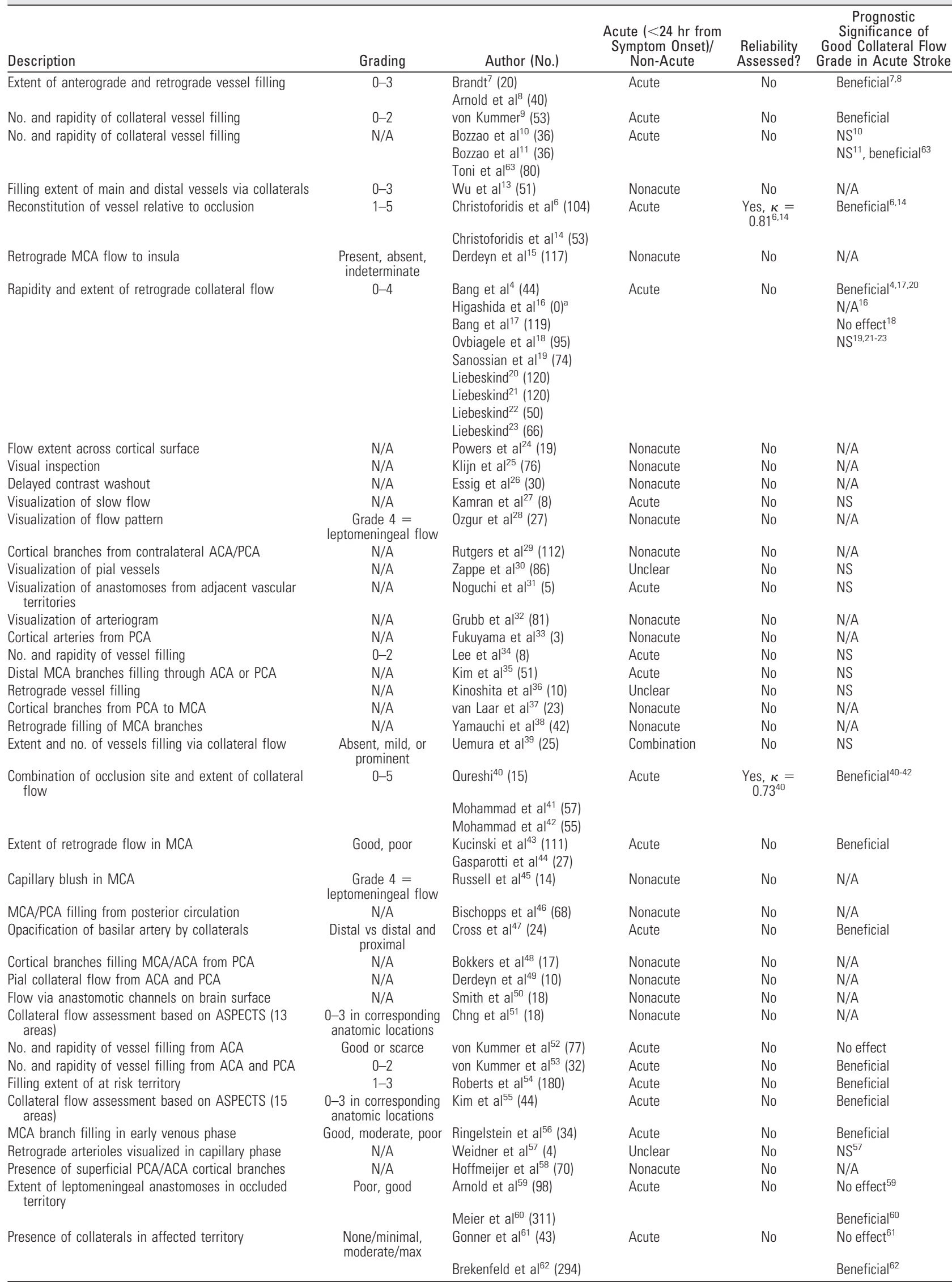

Note:-NS indicates not stated; N/A, not applicable; ASPECTS, Alberta Stroke Program Early CT Score; max., maximal; PCA, posterior cerebral artery

a Proposal on working group on collateral grading. 


\begin{tabular}{|c|c|c|c|c|c|c|}
\hline Modality & Description & Grading & Author (No.) & $\begin{array}{l}\text { Acute }(<24 \mathrm{hr} \text { from } \\
\text { Symptom Onset)/ } \\
\text { Non-Acute }\end{array}$ & $\begin{array}{l}\text { Reliability } \\
\text { Assessed? }\end{array}$ & $\begin{array}{c}\text { Prognostic } \\
\text { Significance } \\
\text { of Good } \\
\text { Collateral Flow } \\
\text { Grade in } \\
\text { Acute Stroke }\end{array}$ \\
\hline Axial CTA-SI & $\begin{array}{l}\text { Extent of perilesional } \\
\text { vessel filling }\end{array}$ & $\begin{array}{l}\text { None, moderate, good, } \\
\text { excellent }\end{array}$ & Liebeskind $^{64}(36)$ & Acute & Yes, ICC $=0.81$ & NS \\
\hline \multirow[t]{2}{*}{ CTA-SI } & $\begin{array}{l}\text { Comparison of } \\
\text { Sylvian collaterals } \\
\text { with contralateral } \\
\text { hemisphere }\end{array}$ & $\begin{array}{l}\text { Absent, less, equal to, } \\
\text { greater than } \\
\text { contralateral } \\
\text { hemisphere, } \\
\text { exuberant }\end{array}$ & Rosenthal et al ${ }^{65}$ (44) & Acute & No & Beneficial ${ }^{65-67}$ \\
\hline & & & $\begin{array}{l}\text { Maas et al }{ }^{66}(135) \\
\text { Lima et al }{ }^{67}(196)\end{array}$ & & & \\
\hline \multirow[t]{2}{*}{ CTA-SI and MPR } & $\begin{array}{c}\text { Extent of perilesional } \\
\text { enhancement }\end{array}$ & Good, poor & Schramm et al ${ }^{68}(20)$ & Acute & Yes, $\kappa=0.494$ & Beneficial ${ }^{68,69}$ \\
\hline & & & Tan et $\mathrm{al}^{69}(113)$ & & & \\
\hline \multirow[t]{2}{*}{$\begin{array}{l}\text { CTA-SI and } \\
\text { reconstructions }\end{array}$} & $\begin{array}{l}\text { MCA filling in } \\
\text { Sylvian fissure }\end{array}$ & $\begin{array}{l}\text { Good, moderate, } \\
\text { absent }\end{array}$ & Wildermuth et al ${ }^{70}(40)$ & Acute & Yes & Beneficial $^{70,71}$ \\
\hline & & & Knauth et al ${ }^{71}$ (21) & & $\begin{array}{l}88 \% \text { agreement } \\
\text { between } 2^{\text {raters }^{71}}\end{array}$ & \\
\hline \multirow[t]{2}{*}{ CTA MIP } & $\begin{array}{l}\text { Extent of filling in } \\
\text { territory of } \\
\text { occluded vessel }\end{array}$ & $0-3$ & Tan et al ${ }^{69}(113)$ & Acute & Yes & Beneficial $^{69.72,73}$ \\
\hline & & & Tan et $\mathrm{al}^{72}(85)$ & & $\begin{array}{l}\kappa=0.669^{69} \\
\text { ICC } 0.87^{72}\end{array}$ & \\
\hline CTA, MIP, CTP & $\begin{array}{l}\text { Retrograde filling of } \\
\text { MCA }\end{array}$ & Good, moderate, poor & $\begin{array}{l}\text { Soares et } \mathrm{al}^{73}(22) \\
\text { Miteff et } \mathrm{al}^{5}(92)\end{array}$ & Acute & Yes & Beneficial \\
\hline (TCTP) & $\begin{array}{l}\text { Extent of perfusion } \\
\text { deficit on TCTP }\end{array}$ & Severe, moderate & Lee et $\mathrm{a}^{34}$ & Acute & $\begin{array}{l}\kappa=0.93 \\
\text { No }\end{array}$ & NS \\
\hline
\end{tabular}

Note:-NS indicates not stated; ICC, intraclass correlation coefficient; CTA-SI, CT angiography source images; MPR, multiplanar reconstruction; MIP, maximum intensity projection; TPCT, triphasic CTP.

Table 4: MR imaging-based grading methods

\begin{tabular}{|c|c|c|c|c|c|}
\hline Modality & Description & Author (No.) & $\begin{array}{c}\text { Acute }(<24 \mathrm{hr} \text { from } \\
\text { Symptom Onset)/ } \\
\text { Nonacute }\end{array}$ & $\begin{array}{l}\text { Reliability } \\
\text { Assessed? }\end{array}$ & $\begin{array}{c}\text { Prognostic } \\
\text { Significance of Good } \\
\text { Collateral Flow Grade } \\
\text { in Acute Stroke }\end{array}$ \\
\hline FADS & Late FADS implies collateral flow & Martel et $\mathrm{al}^{84}(22)$ & Acute & No & NS \\
\hline QMRA & $\begin{array}{l}\text { Increased flow ipsilateral to steno-occlusive } \\
\text { disease }\end{array}$ & Ruland et al ${ }^{83}(16)$ & Nonacute & No & $\mathrm{N} / \mathrm{A}$ \\
\hline Phase-contrast MRA & Flow from posterior to anterior circulation & Schomer et $a^{82}(29)$ & Nonacute & No & $\mathrm{N} / \mathrm{A}$ \\
\hline \multirow[t]{5}{*}{ FLAIR } & $\begin{array}{l}\text { FLAIR hyperintensities as a marker of } \\
\text { collateral flow }\end{array}$ & Liebeskind $^{85}(91)$ & Acute & No & $N^{85,19,27,31,81}$ \\
\hline & & Kamran et $\mathrm{al}^{27}(8)$ & & & \\
\hline & & Noguchi et $\mathrm{al}^{31}(5)$ & & & \\
\hline & & Sanossian et al ${ }^{19}(74)$ & & & \\
\hline & & Lee et $\mathrm{al}^{81}(52)$ & & & \\
\hline T2*-weighted MRI & $\begin{array}{l}\text { Abnormal visualization of leptomeningeal } \\
\text { vessels }\end{array}$ & Hermier et al $\left.\right|^{80}(48)$ & Acute & No & NS \\
\hline PWI & Delayed perfusion sign visualized on PWI & Hermier et $\mathrm{al}^{79}(29)$ & Acute & No & NS \\
\hline ASL & $\begin{array}{l}\text { Quantitative distal collateral flow } \\
\text { measurement }\end{array}$ & Wu et $\mathrm{al}^{13}(51)$ & Nonacute & No & $\mathrm{N} / \mathrm{A}$ \\
\hline TASL & $\begin{array}{l}\text { Collateral flow assessment based on } \\
\text { ASPECTS }\end{array}$ & Chng et $\mathrm{al}^{51}(18)$ & Nonacute & No & N/A \\
\hline CASL & $\begin{array}{l}\text { Collateral flow inferred from delayed } \\
\text { arterial flow }\end{array}$ & Chalela et $\mathrm{al}^{78}(15)$ & Acute & No & NS \\
\hline
\end{tabular}

Note:-NS indicates not stated; N/A, not applicable; FADS, factor analysis of dynamic structures; OMRA, quantitative MRA; TASL, territorial arterial spin labelling; CASL, continuous arterial spin-labeled/labeling; ASPECTS, Alberta Stroke Program Early CT Score.

collateral visualization, and difficulty in finding acoustic windows are limitations of TCD, though these are offset by the lack of radiation and contrast requirements. ${ }^{90}$ Flow diversion on TCD, defined as increased flow velocity in ipsilateral ACA/ 


\begin{tabular}{|c|c|c|c|c|}
\hline Description & Author (No.) & $\begin{array}{c}\text { Acute }(<24 \mathrm{hr} \text { from } \\
\text { Symptom Onset)/Nonacute }\end{array}$ & $\begin{array}{l}\text { Reliability } \\
\text { Assessed? }\end{array}$ & $\begin{array}{c}\text { Significance of Good } \\
\text { Collateral Flow Grade } \\
\text { in Acute Stroke }\end{array}$ \\
\hline Asymmetry of flow in ipsilateral ACA and PCA & Zanette et $\mathrm{al}^{77}(56)$ & Acute & No & NS \\
\hline Asymmetric P2 flow and reduced pulsatility & $\begin{array}{l}\text { Reinhard et } \mathrm{al}^{76}(30) \\
\text { Reinhard et } \mathrm{al}^{75}(111)\end{array}$ & Nonacute & No & $\mathrm{N} / \mathrm{A}$ \\
\hline $\begin{array}{l}\text { Asymmetric mean blood velocity in proximal } \\
\text { ACA or P2 segment of ACA }\end{array}$ & Muller and Schimrigk ${ }^{2}(48)$ & Nonacute & No & $\mathrm{N} / \mathrm{A}$ \\
\hline Accelerated flow in $\mathrm{A} 1$ segment of ACA & Kaps et $\mathrm{al}^{74}(23)$ & Acute & No & NS \\
\hline Flow direction relative to Doppler probe & Hennerici et al ${ }^{86, a}$ & Unclear & No & NS \\
\hline Asymmetric flow velocity and pulsatility index & Kim et $\mathrm{al}^{35}(51)$ & Acute & No & NS \\
\hline
\end{tabular}

Note:-NS indicates not stated; N/A, not applicable.

a Number not stated.

PCA, did correlate with angiographic collateral grade when methods were compared, suggesting a possible role for TCD to measure LMF. ${ }^{35}$

When collaterals were measured by using DSA, CTA, and MR imaging, CTA compared favorably, but the methods used for grading LMF on CTA were not clearly stated, so this finding must be interpreted with caution. ${ }^{36}$

\section{Conclusions}

The presence of flow in leptomeningeal collaterals is linked with positive outcomes after stroke, but there is little consistency in the methods used to grade the efficacy of collateral flow. Although the importance of leptomeningeal collaterals is consistently reported, the inconsistency in imaging methods and grading currently limits the emphasis that can be placed on collaterals. For targeting collateral vessels in stroke therapeutic strategies, consistency in examining their extent at baseline is required to permit further expansion of this area. At present, conventional angiography remains the method that can best measure collateral extent and number, but CT-based techniques, which have demonstrated good interobserver reliability and correlation with clinical outcome, may provide an accessible and reliable assessment method for grading collateral flow in a larger patient population, particularly with the development of dynamic CTA combined with perfusion imaging. MR imaging and TCD have been used less frequently than angiography or CT but can also provide noninvasive measurements of LMF.

\section{Appendix}

Search Strategy MEDLINE (1950 to July Week 1 2009) and Embase before 1980 to 2009 Week 32 .

1) stroke.mp. or ${ }^{\star}$ Stroke/ (112119)

2) acute stroke.mp. or ${ }^{\star}$ Stroke/ (34761)

$3){ }^{\star}$ Adult/ or ${ }^{\star}$ Aged/ or ${ }^{\star}$ Ischemic Attack, Transient/ or ${ }^{\star}$ Cerebrovascular Circulation/ or ${ }^{\star}$ Cerebrovascular Disorders/ or ${ }^{\star}$ Brain/ or ${ }^{\star}$ Middle Aged/ or ${ }^{\star}$ Brain Ischemia/ or ischemic stroke.mp. or ${ }^{\star}$ Cerebral Infarction/ (93464)

4) cerebral infarction.mp. or ${ }^{\star}$ Cerebral Infarction/ (13177)

5) occlusion.mp. (91391)

6) stenosis.mp. or Constriction, Pathologic/ (85260)

7) carotid stenosis.mp. or ${ }^{\star}$ Carotid Stenosis/ (7417)

8) ${ }^{\star}$ Cerebral Arteries/ or ${ }^{\star}$ Cerebrovascular Disorders/ or ${ }^{\star}$ Aged/ or ${ }^{\star}$ Carotid Artery Diseases/ or ${ }^{\star}$ Ischemic Attack,
Transient/ or ${ }^{\star}$ Cerebral Infarction/ or ${ }^{\star}$ Arterial Occlusive Diseases/ or intracranial occlusion.mp. or ${ }^{\star}$ Stroke/ (70577)

9) middle cerebral artery occlusion.mp. or ${ }^{\star}$ Infarction, Middle Cerebral Artery/ (7330)

10) ${ }^{\star}$ Thrombosis/ or ${ }^{\star}$ Intracranial Thrombosis/ or ${ }^{\star} \mathrm{Ca}$ rotid Artery Thrombosis/ or * Intracranial Embolism and Thrombosis"/ or thrombosis.mp. (116053)

11) clinical outcome.mp. (26854)

12) contrast media.mp. or ${ }^{\star}$ Contrast Media/ (11586)

13) tomography, $\mathrm{x}$-ray computed.mp. or ${ }^{\star}$ Tomography, X-Ray Computed/ (55062)

14) *Angiography, Digital Subtraction/ or *Angiography/ or Angiography.mp. or ${ }^{\star}$ Cerebral Angiography/ or ${ }^{\star}$ Magnetic Resonance Angiography/ (113286)

15) CT angiography.mp. (3058)

16) CT angiogram.mp. (148)

17) CT angiography source images.mp. (7)

18) ${ }^{\star}$ Brain Ischemia/ or ${ }^{\star}$ Brain/ or ${ }^{\star}$ Diffusion Magnetic Resonance Imaging/ or ${ }^{\star}$ Magnetic Resonance Imaging/ or MR, diffusion weighted.mp. (111259)

19) MR angiography.mp. or ${ }^{\star}$ Magnetic Resonance Angiography/ (12630)

20) digital subtraction angiography.mp. or *Angiography, Digital Subtraction/ (8851)

21) angiogram.mp. (5291)

22 * Ultrasonography, Doppler, Transcranial/ or transcranial.mp. (15831)

23) ${ }^{\star}$ Cerebrovascular Circulation/ or ${ }^{\star}$ Collateral Circulation/ or pial collaterals.mp. or ${ }^{\star}$ Cerebral Arteries/ (4354)

24) leptomeningeal collaterals.mp. (35)

25) collateral circulation.mp. or ${ }^{\star}$ Collateral Circulation/ (6309)

26) collateral vessels.mp. (1376)

27) collateral flow.mp. (1333)

28) collateral blood supply.mp. (203)

29) CT perfusion.mp. (380)

30) recanalization.mp. (7177)

$31{ }^{*}$ Thrombolytic Therapy/ or thrombolysis.mp. or * Stroke/ (45637)

32) angiogram.m_titl. (312)

33) angiography.m_titl. (15333)

34) collateral.m_titl. (3356)

35) 33 or 32 or 21 or 17 or 12 or 20 or 15 or 14 or 22 or 34 or 30 or 13 or 16 or 19 (196091) 
36) 6 or 11 or 3 or 7 or 9 or 2 or 8 or 1 or 4 or 30 or 10 or 5 (460879)

37) 27 or 25 or 28 or 30 or 24 or 26 or 23 (17675)

38) 35 , or 29 (196193)

39) 38 , and 36 and 37 (9774)

40) limit 39 to humans (8311)

41) limit 40 to English language (6887)

42) from 41 keep $84,96,99,126,143,161,181,241,247,262-$ 263,290,304,311-312,314,400,439,446,489,492,507,532,613, $616,623,694,891,949(29)$.

Disclosures: Ferghal McVerry — supported by an award from Chest Heart and Stroke Scotland* and the Translational Medicine Research Collaboration. David S. LiebeskindRELATED: Grant. NINDS-NIH;* UNRELATED: Consultancy. Concentric Medical, CoAxia. Keith W. Muir-supported by the Scottish Imaging Network, A Platform for Scientific Excellence (SINAPSE) network; UNRELATED: Consultancy. ReNeuron, Lundbeck, MScience, Comments: preparation for a clinical trial in relation to stem cells (ReNeuron), ${ }^{*}$ an ongoing trial in acute stroke thrombolysis (Lundbeck), ${ }^{*}$ analysis of clinical trial data from acute stroke regenerative drug treatment (MScience); ${ }^{*}$ Grants/Grants Pending: Penumbra, Concentric, ev3. ${ }^{*}$ ("Money paid to institution)

\section{References}

1. Brozici M, van der Zwan A, Hillen B. Anatomy and functionality of leptomeningeal anastomoses: a review. Stroke 2003;34:2750-62

2. Muller M, Schimrigk K. Vasomotor reactivity and pattern of collateral blood flow in severe occlusive carotid artery disease. Stroke 1996;27:296-99

3. Liebeskind DS. Collateral circulation. Stroke 2003;34:2279-84

4. Bang OY, Saver JL, Buck BH, et al. Impact of collateral flow on tissue fate in acute ischaemic stroke. J Neurol Neurosurg Psychiatry 2008;79:625-29

5. Miteff F, Levi CR, Bateman GA, et al. The independent predictive utility of computed tomography angiographic collateral status in acute ischaemic stroke. Brain 2009;132:2231-38

6. Christoforidis GA, Karakasis C, Mohammad Y, et al. Predictors of hemorrhage following intra-arterial thrombolysis for acute ischemic stroke: the role of pial collateral formation. AJNR Am J Neuroradiol 2009;30:165-70

7. Brandt T. Survival with basilar artery occlusion. Cerebrovasc Dis 1995;5:182-87

8. Arnold M, Nedeltchev K, Schroth G, et al. Clinical and radiological predictors of recanalisation and outcome of 40 patients with acute basilar artery occlusion treated with intra-arterial thrombolysis. J Neurol Neurosurg Psychiatry 2004;75:857-62

9. von Kummer R. Effects of recanalization and collateral blood supply on infarct extent and brain edema after middle cerebral artery occlusion. Cerebrovasc Dis 1993;3:252-55

10. Bozzao L, Fantozzi LM, Bastianello S, et al. Early collateral blood supply and late parenchymal brain damage in patients with middle cerebral artery occlusion. Stroke 1989;20:735-40

11. Bozzao L, Bastianello S, Fantozzi LM, et al. Correlation of angiographic and sequential CT findings in patients with evolving cerebral infarction. AJNR Am J Neuroradiol 1989;10:1215-22

12. Toni D, Fiorelli M, De Michele M, et al. Clinical and prognostic correlates of stroke subtype misdiagnosis within $\mathbf{1 2}$ hours from onset. Stroke 1995; 26:1837-40

13. Wu B, Wang X, Guo J, et al. Collateral circulation imaging: MR perfusion territory arterial spin-labeling at 3T. AJNR Am J Neuroradiol 2008;29:1855-60

14. Christoforidis GA, Mohammad Y, Kehagias D, et al. Angiographic assessment of pial collaterals as a prognostic indicator following intra-arterial thrombolysis for acute ischemic stroke. AJNR Am J Neuroradiol. 2005;26:1789-97

15. Derdeyn CP, Shaibani A, Moran CJ, et al. Lack of correlation between pattern of collateralization and misery perfusion in patients with carotid occlusion. Stroke 1999;30:1025-32

16. Higashida RT, Furlan AJ, Roberts $\mathrm{H}$, et al. Trial design and reporting standards for intra-arterial cerebral thrombolysis for acute ischemic stroke. Stroke 2003;34:e109-37

17. Bang OY, Saver JL, Alger JR, et al. Determinants of the distribution and severity of hypoperfusion in patients with ischemic stroke. Neurology 2008; 71:1804-11

18. Ovbiagele B, Saver JL, Starkman S, et al. Statin enhancement of collateralization in acute stroke. Neurology 2007;68:2129-31

19. Sanossian N, Saver JL, Alger JR, et al. Angiography reveals that fluid-attenuated inversion recovery vascular hyperintensities are due to slow flow, not thrombus. AJNR Am J Neuroradiol 2009;30:564-68

20. Liebeskind DS. Angiographic collaterals and outcome in mechanical thrombolysis. Stroke 2005;36:449
21. Liebeskind DS. Clinical predictors of angiographic collaterals in acute ischemic stroke. Stroke. 2005;36:450

22. Liebeskind DS. Benign oligemia reflects collateral perfusion: MRI and angiography of low perfusion hyperemia in humans. Stroke 2008;39:577

23. Liebeskind DS, Sanossian N, Alger JR, et al. Gradient echo MRI phase mismapping reveals angiographic correlated in acute ischemic stroke. Stroke 2006;37:637

24. Powers WJ, Press GA, Grubb RL Jr, et al. The effect of hemodynamically significant carotid artery disease on the hemodynamic status of the cerebral circulation. Ann Intern Med 1987;106:27-34

25. Klijn CJ, Kappelle LJ, van Huffelen AC, et al. Recurrent ischemia in symptomatic carotid occlusion: prognostic value of hemodynamic factors. Neurology 2000;55:1806-12

26. Essig M, von Kummer R, Egelhof T, et al. Vascular MR contrast enhancement in cerebrovascular disease. AJNR Am J Neuroradiol 1996;17:887-94

27. Kamran S, Bates V, Bakshi R, et al. Significance of hyperintense vessels on FLAIR MRI in acute stroke. Neurology 2000;55:265-69

28. Ozgur HT, Kent Walsh T, Masaryk A, et al. Correlation of cerebrovascular reserve as measured by acetazolamide-challenged SPECT with angiographic flow patterns and intra- or extracranial arterial stenosis. AJNR Am J Neuroradiol 2001;22:928-36

29. Rutgers DR, Klijn CJ, Kappelle LJ, et al. Recurrent stroke in patients with symptomatic carotid artery occlusion is associated with high-volume flow to the brain and increased collateral circulation. Stroke 2004;35:1345-49

30. Zappe L, Juhasz J, Vidovszky T. Relationship of collateral circulation and prognosis in cerebral arterial occlusion. Acta Neurochir (Wien) 1966;14:225-37

31. Noguchi K, Ogawa T, Inugami A, et al. MRI of acute cerebral infarction: a comparison of FLAIR and T2-weighted fast spin-echo imaging. Neuroradiology 1997;39:406-10

32. Grubb RL Jr, Derdeyn CP, Fritsch SM, et al. Importance of hemodynamic factors in the prognosis of symptomatic carotid occlusion. JAMA 1998;280:1055-60

33. Fukuyama H, Akiguchi I, Kameyama M, et al. Krypton-81m single photon emission tomography and the collateral circulation in carotid occlusion: the role of the circle of Willis and leptomeningeal anastomoses. J Neurol 1983;230:7-17

34. Lee KH, Cho SJ, Byun HS, et al. Triphasic perfusion computed tomography in acute middle cerebral artery stroke: a correlation with angiographic findings. Arch Neurol 2000;57:990-99

35. Kim Y, Sin DS, Park HY, et al. Relationship between flow diversion on transcranial Doppler sonography and leptomeningeal collateral circulation in patients with middle cerebral artery occlusive disorder. J Neuroimaging 2009;19:23-26

36. Kinoshita T, Ogawa T, Kado H, et al. CT angiography in the evaluation of intracranial occlusive disease with collateral circulation: comparison with MR angiography. Clin Imaging 2005;29:303-06

37. van Laar PJ, Hendrikse J, Klijn CJ, et al. Symptomatic carotid artery occlusion: flow territories of major brain-feeding arteries. Radiology 2007;242:526-34

38. Yamauchi H, Kudoh T, Sugimoto K, et al. Pattern of collaterals, type of Infarcts, and haemodynamic impairment in carotid artery occlusion. J Neurol Neurosurg Psychiatry 2004;75:1697-701

39. Uemura A, O'Uchi T, Kikuchi Y, et al. Prominent laterality of the posterior cerebral artery at three-dimensional time-of-flight MR angiography in m1segment middle cerebral artery occlusion. AJNR Am J Neuroradiol 2004;25:88-91

40. Qureshi AI. New grading system for angiographic evaluation of arterial occlusions and recanalization response to intra-arterial thrombolysis in acute ischemic stroke. Neurosurgery 2002;50:1405-14, discussion 1414-15

41. Mohammad Y, Xavier AR, Christoforidis G, et al. Qureshi grading scheme for angiographic occlusions strongly correlates with the initial severity and inhospital outcome of acute ischemic stroke. J Neuroimaging. 2004;14:235-41

42. Mohammad YM, Christoforidis GA, Bourekas EC, et al. Qureshi grading scheme predicts subsequent volume of brain infarction following intra-arterial thrombolysis in patients with acute anterior circulation ischemic stroke. J Neuroimaging 2008;18:262-67

43. Kucinski T, Koch C, Eckert B, et al. Collateral circulation is an independent radiological predictor of outcome after thrombolysis in acute ischaemic stroke. Neuroradiology 2003;45:11-18

44. Gasparotti R, Grassi M, Mardighian D, et al. Perfusion CT in patients with acute ischemic stroke treated with intra-arterial thrombolysis: predictive value of infarct core size on clinical outcome. AJNR Am J Neuroradiol 2009;30:722-27

45. Russell SM, Woo HH, Siller K, et al. Evaluating middle cerebral artery collateral blood flow reserve using acetazolamide transcranial Doppler ultrasound in patients with carotid occlusive disease. Surg Neurol 2008;70:466-70, discussion 470

46. Bisschops RH, Klijn CJ, Kappelle LJ, et al. Collateral flow and ischemic brain lesions in patients with unilateral carotid artery occlusion. Neurology 2003;60:1435-41

47. Cross DT 3rd, Moran CJ, Akins PT, et al. Collateral circulation and outcome after basilar artery thrombolysis. AJNR Am J Neuroradiol 1998;19:1557-63 
48. Bokkers RP, van Laar PJ, van de Ven KC, et al. Arterial spin-labeling MR imaging measurements of timing parameters in patients with a carotid artery occlusion. AJNR Am J Neuroradiol 2008;29:1698-703

49. Derdeyn CP, Powers WJ, Grubb RL Jr. Hemodynamic effects of middle cerebral artery stenosis and occlusion. AJNR Am J Neuroradiol 1998;19:1463-69

50. Smith HA, Thompson-Dobkin J, Yonas H, et al. Correlation of xenon-enhanced computed tomography-defined cerebral blood flow reactivity and collateral flow patterns. Stroke 1994;25:1784-87

51. Chng SM, Petersen ET, Zimine I, et al. Territorial arterial spin labeling in the assessment of collateral circulation: comparison with digital subtraction angiography. Stroke 2008;39:3248-54

52. von Kummer R, Holle R, Rosin L, et al. Does arterial recanalization improve outcome in carotid territory stroke? Stroke 1995;26:581-87

53. von Kummer R, Hacke W. Safety and efficacy of intravenous tissue plasminogen activator and heparin in acute middle cerebral artery stroke. Stroke 1992;23:646-52

54. Roberts HC, Dillon WP, Furlan AJ, et al. Computed tomographic findings in patients undergoing intra-arterial thrombolysis for acute ischemic stroke due to middle cerebral artery occlusion: results from the PROACT II trial. Stroke 2002;33:1557-65

55. Kim JJ, Fischbein NJ, Lu Y, et al. Regional angiographic grading system for collateral flow: correlation with cerebral infarction in patients with middle cerebral artery occlusion. Stroke 2004;35:1340-44

56. Ringelstein EB, Biniek R, Weiller C, et al. Type and extent of hemispheric brain infarctions and clinical outcome in early and delayed middle cerebral artery recanalization. Neurology 1992;42:289-98

57. Weidner $\mathrm{W}$, Hanafeewmarkham $\mathrm{CH}$. Intracranial collateral circulation via leptomeningeal and rete mirabile anastomoses. Neurology 1965;15:39-48

58. Hofmeijer J, Klijn CJ, Kappelle LJ, et al. Collateral circulation via the ophthalmic artery or leptomeningeal vessels is associated with impaired cerebral vasoreactivity in patients with symptomatic carotid artery occlusion. Cerebrovasc Dis 2002;14:22-26

59. Arnold M, Schroth G, Nedeltchev K, et al. Intra-arterial thrombolysis in $\mathbf{1 0 0}$ patients with acute stroke due to middle cerebral artery occlusion. Stroke 2002;33:1828-33

60. Meier N, Nedeltchev K, Brekenfeld C, et al. Prior statin use, intracranial hemorrhage, and outcome after intra-arterial thrombolysis for acute ischemic stroke. Stroke 2009;40:1729-37

61. Gonner F, Remonda L, Mattle H, et al. Local intra-arterial thrombolysis in acute ischemic stroke. Stroke 1998;29:1894-900

62. Brekenfeld C, Remonda L, Nedeltchev K, et al. Symptomatic intracranial haemorrhage after intra-arterial thrombolysis in acute ischaemic stroke: assessment of 294 patients treated with urokinase. J Neurol Neurosurg Psychiatry 2007;78:280-85

63. Toni D, Fiorelli M, Bastianello S, et al. Acute ischemic strokes improving during the first $\mathbf{4 8}$ hours of onset: predictability, outcome, and possible mechanisms - a comparison with early deteriorating strokes. Stroke 1997;28:10-14

64. Liebeskind D. A novel CT angiography scale for assessment of collaterals in acute stroke. Stroke 2003;34:265

65. Rosenthal ES, Schwamm LH, Roccatagliata L, et al. Role of recanalization in acute stroke outcome: rationale for a CT angiogram-based "benefit of recanalization" model. AJNR Am J Neuroradiol 2008;29:1471-75

66. Maas MB, Lev MH, Ay H, et al. Collateral vessels on CT angiography predict outcome in acute ischemic stroke. Stroke 2009;40:3001-05

67. Lima FO, Furie KL, Silva GS, et al. The pattern of leptomeningeal collaterals on CT angiography is a strong predictor of long-term functional outcome in stroke patients with large vessel intracranial occlusion. Stroke 41:2316-22

68. Schramm P, Schellinger PD, Fiebach JB, et al. Comparison of CT and CT angiography source images with diffusion-weighted imaging in patients with acute stroke within 6 hours after onset. Stroke 2002;33:2426-32
69. Tan JC, Dillon WP, Liu S, et al. Systematic comparison of perfusion-CT and CT-angiography in acute stroke patients. Ann Neurol 2007;61:533-43

70. Wildermuth S, Knauth M, Brandt T, et al. Role of CT angiography in patient selection for thrombolytic therapy in acute hemispheric stroke. Stroke 1998;29:935-38

71. Knauth $\mathrm{M}$, von Kummer R, Jansen $\mathrm{O}$, et al. Potential of CT angiography in acute ischemic stroke. AJNR Am J Neuroradiol 1997;18:1001-10

72. Tan IY, Demchuk AM, Hopyan J, et al. CT angiography clot burden score and collateral score: correlation with clinical and radiologic outcomes in acute middle cerebral artery infarct. AJNR Am J Neuroradiol 2009;30:525-31

73. Soares BP, Tong E, Hom J, et al. Reperfusion is a more accurate predictor of follow-up infarct volume than recanalization: a proof of concept using CT in acute ischemic stroke patients. Stroke 2010;41:e34-40. Epub 2009 Nov 12

74. Kaps M, Damian MS, Teschendorf U, et al. Transcranial Doppler ultrasound findings in middle cerebral artery occlusion. Stroke 1990;21:532-37

75. Reinhard M, Muller T, Guschlbauer B, et al. Dynamic cerebral autoregulation and collateral flow patterns in patients with severe carotid stenosis or occlusion. Ultrasound Med Biol 2003;29:1105-13

76. Reinhard M, Muller T, Roth M, et al. Bilateral severe carotid artery stenosis or occlusion: cerebral autoregulation dynamics and collateral flow patterns. Acta Neurochir (Wien) 2003;145:1053-59, discussion 1059-60

77. Zanette EM, Roberti C, Mancini G, et al. Spontaneous middle cerebral artery reperfusion in ischemic stroke: a follow-up study with transcranial Doppler. Stroke 1995;26:430-33

78. Chalela JA, Alsop DC, Gonzalez-Atavales JB, et al. Magnetic resonance perfusion imaging in acute ischemic stroke using continuous arterial spin labeling. Stroke 2000;31:680-87

79. Hermier M, Ibrahim AS, Wiart M, et al. The delayed perfusion sign at MRI J Neuroradiol 2003;30:172-79

80. Hermier M, Nighoghossian N, Derex L, et al. Hypointense leptomeningea vessels at T2*-weighted MRI in acute ischemic stroke. Neurology 2005; 65:652-53

81. Lee KY, Latour LL, Luby M, et al. Distal hyperintense vessels on flair: an MRI marker for collateral circulation in acute stroke? Neurology 2009;72:1134-39

82. Schomer DF, Marks MP, Steinberg GK, et al. The anatomy of the posterior communicating artery as a risk factor for ischemic cerebral infarction. $N$ Eng J Med 1994;330:1565-70

83. Ruland S, Ahmed A, Thomas K, et al. Leptomeningeal collateral volume flow assessed by quantitative magnetic resonance angiography in large-vessel cerebrovascular disease. J Neuroimaging 2009;19:27-30

84. Martel AL, Allder SJ, Delay GS, et al. Perfusion MRI of infarcted and noninfarcted brain tissue in stroke: a comparison of conventional hemodynamic imaging and factor analysis of dynamic studies. Invest Radiol 2001;36:378-85

85. Liebeskind D. Intravascular deoxygenation of leptomeningeal collaterals detected with gradient-echo MRI. Stroke 2004;35:266

86. Hennerici M, Rautenberg W, Schwartz A. Transcranial Doppler ultrasound for the assessment of intracranial arterial flow velocity. Part 2. Evaluation of intracranial arterial disease. Surg Neurol 1987;27:523-32

87. The Thrombolysis in Myocardial Infarction (TIMI) trial phase I findings: TIMI study group. $N$ Engl J Med 1985;312:932-36

88. Saito I, Segawa H, Shiokawa Y, et al. Middle cerebral artery occlusion: correlation of computed tomography and angiography with clinical outcome. Stroke 1987; $18: 863-68$

89. Siebert E, Bohner G, Dewey M, et al. 320-slice CT neuroimaging: initial clinica experience and image quality evaluation. Br J Radiol 2009;82:561-70. Epub 2009 Feb 16

90. Marinoni M, Ginanneschi A, Forleo P, et al. Technical limits in transcranial Doppler recording: on adequate acoustic windows. Ultrasound Med Biol 1997; 23:1275-77 